\title{
The ADP receptor $\mathrm{P}_{2} \mathrm{Y}_{1}$ mediates t-PA release in pigs during cardiac ischemia
}

\author{
Goran K. Olivecrona, \\ Department of Cardiology, Lund University Hospital, Lund University, Lund 22185, Sweden \\ Matthias Götberg, \\ Department of Cardiology, Lund University Hospital, Lund University, Lund 22185, Sweden \\ Jan Harnek, \\ Department of Radiology, Lund University, Lund, Sweden
}

Kenneth A. Jacobson,

Molecular Recognition Section, NIH, Bethesda, MD, USA

Sverker Jern, and

Clinical Experimental Research Laboratory, Heart and Lung Institute Sahlgrenska University Hospital, Gothenburg, Sweden

\section{David Erlinge}

Department of Cardiology, Lund University Hospital, Lund University, Lund 22185, Sweden

\begin{abstract}
Background-The endothelial ADP receptor $\mathrm{P}_{2} \mathrm{Y}_{1}$ is responsible for a large part of the reactive hyperemia following cardiac ischemia. Tissue plasminogen activator (t-PA) increases during reactive hyperemia. We postulated that the release of t-PA during reactive hyperemia could be mitigated through blocking the coronary endothelial $\mathrm{P}_{2} \mathrm{Y}_{1}$ receptor.
\end{abstract}

Methods-t-PA was measured in peripheral arterial blood and locally in the venous blood from the coronary sinus in a porcine model. The stable ADP analogue 2-MeSADP $\left(10^{-5} \mathrm{M}\right)$, alone or as co-infusion with a selective $\mathrm{P}_{2} \mathrm{Y}_{1}$ receptor blocker, MRS2179 $\left(10^{-3} \mathrm{M}\right)$ was locally delivered in the left anterior descending artery through the tip of a coronary angioplasty balloon. In separate pigs the coronary artery was occluded with the balloon for $10 \mathrm{~min}$. During the first and tenth minute of coronary ischemia, $2.5 \mathrm{ml}$ of MRS2179 $\left(10^{-3} \mathrm{M}\right)$ was delivered distal to the occlusion in 8 pigs, 10 pigs were used as controls.

Results-2-MeSADP increased levels of t-PA in the coronary sinus, which could be significantly inhibited by co-infusion with MRS2179. During cardiac ischemia and reperfusion, tPA increased significantly, an effect that could be significantly inhibited by MRS2179.

Conclusions-Intra coronary administered MRS2179, a selective $\mathrm{P}_{2} \mathrm{Y}_{1}$ receptor blocker, significantly reduces the increased levels of t-PA caused by both 2-MeSADP and cardiac ischemia in coronary arteries. Thus, ADP acting on the endothelial $\mathrm{P}_{2} \mathrm{Y}_{1}$ receptor may mediate release of $\mathrm{t}-$ 
PA during ischemia and post-ischemic hyperemia, an effect that may counteract some of the platelet activating effects of ADP.

\section{Keywords}

ADP; P2Y1; t-PA; Coronary; Ischemia

\section{Introduction}

Tissue-type plasminogen activator (t-PA) is an enzyme of great importance in maintaining the endothelial wall of blood vessels free of thrombi formation. t-PA itself is synthesized and stored both in endothelial cells as well as vascular neurons $[1,2]$. Release of t-PA is caused by several substances ( $\beta 2$ receptor activators, Platelet activating factor (PAF), Isoproterenol, Metacholine, Bradykinin, and extracellular nucleotides (such as ATP, ADP and UTP) as well as by cardiac sympathetic nerve stimulation and local ischemia [3-11]. The actual mechanism by which the above-mentioned factors cause the release of t-PA is still unclear but it has been postulated that the release may be an endothelium derived hyperpolarization factor (EDHF) mediated phenomenon [12].

Post-ischemic reactive hyperemia is the brief, enormous increase in blood-flow seen once blood flow is re-established to a previously ischemic tissue or organ, compared to flow at baseline before ischemia. The blood flow is much larger (up to 15-20 times the flow seen at baseline) than the incurred oxygen debt would require, and the full mechanism is not yet completely understood $[13,14]$.

ADP activates $\mathrm{P}_{2} \mathrm{Y}_{1}$ receptors on the endothelium [15] and on platelets [16] which causes smooth muscle cell relaxation and activation of platelets in arteries. Endothelial $\mathrm{P}_{2} \mathrm{Y}_{1^{-}}$ receptors, when activated by ADP, mediate smooth muscle cell (SMC) relaxation through both NO and EDHF [17, 18]. We could recently show that coronary reactive hyperemia was significantly reduced by the $\mathrm{P}_{2} \mathrm{Y}_{1}$ blocker MRS 2179, indicating that ADP mediates a major part of reactive hyperemia via its activation of endothelial $\mathrm{P}_{2} \mathrm{Y}_{1}$ receptors [19].

We therefore postulated that by blocking the $\mathrm{P}_{2} \mathrm{Y}_{1}$ receptor, and thus EDHF, we would find a decreased release of t-PA during and immediately following cardiac ischemia.

\section{Methods}

Animals

A total of 27 healthy domestic male and female pigs weighing $25 \mathrm{~kg}$ were fasted overnight with free access to water and were premedicated with azaperone (Stresnil Vet., Leo; Helsingborg, Sweden), $2 \mathrm{mg} / \mathrm{kg}$ intramuscularly $30 \mathrm{~min}$ before the procedure. After induction of anesthesia with thiopental $5-25 \mathrm{mg} / \mathrm{kg}$ (Pentothal, Abbott, Stockholm, Sweden), the animals were orally intubated with cuffed endotracheal tubes. A slow infusion of $1.25 \mu \mathrm{l} / \mathrm{ml}$ Fentanyl (Fentanyl, Pharmalink AB, Stockholm, Sweden) in Ringer's acetate solution was started at a rate of $1.5 \mathrm{ml} / \mathrm{min}$ and adjusted as needed. Mechanical ventilation was then established with a Siemens-Elema 300B ventilator in the volume-controlled mode. Initial settings were: respiratory rate of $15 / \mathrm{min}$, tidal volume of $10 \mathrm{ml} / \mathrm{kg}$, and positive end- 
expiratory pressure of $5 \mathrm{~cm} \mathrm{H}_{2} \mathrm{O}$. Min volume was subsequently adjusted in order to obtain normocapnia (35-40 mmHg). The animals were ventilated with a mixture of dinitrous oxide $(70 \%)$ and oxygen $(30 \%)$. Anesthesia was complemented with small intermittent doses of 5 mg meprobamat (Mebumal, DAK, Copenhagen, Denmark) and thiopental (Pentothal, Abbott, Stockholm, Sweden), if needed.

A 6 F introducer sheath (Boston Scientific Scimed, Maple Grove, MN, USA) was inserted into the surgically exposed left femoral artery. The side port of the introducer was connected to a pressure transducer and balanced to atmospheric pressure with zero reference at the mid-axillary level for continuously monitoring of the arterial pressure. A three-lead ECG was displayed on the same monitor as the pressure curve (78342 A, Hewlett and Packard GMBH, Boeblingen, Germany). A 14 F introducer sheath (Boston Scientific Scimed, Maple Grove, MN, USA) was inserted into the surgically exposed right jugular vein through which a short 10 F Coronary Sinus catheter of our own design was introduced into the ostium of the Azygos vein in the right atrium. Then a $6 \mathrm{~F}$ coronary MPA catheter (Onset, Cordis Co. Miami, FL, USA) was passed through the $10 \mathrm{~F}$ catheter and the Azygos Vein and into the Coronary Sinus. An angiogram was obtained using 5-10 $\mathrm{ml}$ of the contrast medium Omnipaque ${ }^{\mathrm{TM}} 300 \mathrm{mg} \mathrm{I}^{-} / \mathrm{ml}$ (Nycomed, Oslo, Norway) to ensure correct positioning of the catheter.

A 6 F introducer sheath (Boston Scientific Scimed, Maple Grove, MN, USA) was inserted into the surgically exposed left carotid artery upon which a 6F JL 3.5 Wiseguide ${ }^{\mathrm{TM}}$ (Boston Scientific Scimed, Maple Grove, MN, USA) was inserted into the left main coronary artery and 10,000 IU of Heparin was administered. An angiogram was obtained using 8-10 ml of the contrast medium Omnipaque ${ }^{\mathrm{TM}} 300 \mathrm{mg} \mathrm{I}^{-} / \mathrm{ml}$ (Nycomed, Oslo, Norway) to ensure correct positioning of the catheter. The catheter was used to place a 0.014-in., $12 \mathrm{MHz}$ pulsed Doppler flow velocity transducer (Jometrics Flowire, Jomed NV) into the midportion of the left anterior descending artery (LAD) and a 0.014-in. PT choice ${ }^{\mathrm{TM}}$ guidewire (Boston Scientific Scimed, Maple Grove, MN, USA) into the distal portion of the LAD. A $3.0 \mathrm{~mm} \times 20 \mathrm{~mm}$ over the wire Maverick ${ }^{\mathrm{TM}}$ angioplasty balloon (Boston Scientific Scimed, Maple Grove, MN, USA) was then positioned in the mid portion of the LAD but proximal to the flow velocity transducer followed by the withdrawal of the PT choice guidewire. Continuous coronary velocity flow profiles were displayed and recorded using the Doppler flow wire connected to a FloMap monitor (Cardiometrics, Mountain View, CA). Flow was measured in units of average peak velocity (APV) in centimeters per second. All radiological procedures were performed in an experimental catheterization laboratory, (Shimadzu Corp., Kyoto, Japan).

The lumen of the angioplasty balloon was connected to an infusion pump, Asena CC (Alavis Medical, Bristol, England). The infusion pump was initially used to infuse Ringeŕs acetate solution and $\mathrm{NaCl}(0.9 \%)$ at rates of $0.5,1,2,4$ and $6 \mathrm{ml} / \mathrm{min}$ in the LAD through the inner lumen of the angioplasty balloon catheter. At an infusion rate of $2 \mathrm{ml} / \mathrm{min}$ or less, there were no effects on blood flow in the LAD as earlier reported [19].

In five pigs 2-MeSADP $\left(10^{-5} \mathrm{M}\right.$ dissolved in $\left.\mathrm{NaCl} 0.9 \%\right)$ at $1 \mathrm{ml} / \mathrm{min}$ was infused and FloMap measurements were performed. 2-MeSADP $\left(10^{-5} \mathrm{M}\right)$ was then infused with MRS 
$2179\left(10^{-3} \mathrm{M}\right)$ at a rate of $1 \mathrm{ml} / \mathrm{min}$. To test the effect of MRS 2179 on t-PA release following reactive hyperemia, an occlusion of the LAD, distal to the first diagonal branch, was achieved with inflation of the angioplasty balloon for a period of $10 \mathrm{~min}$. During the first and tenth min of coronary ischemia, $2.5 \mathrm{ml}$ of MRS2179 $\left(10^{-3} \mathrm{M}\right)$ was delivered distal to the occlusion in the LAD in eight pigs. Ten pigs were used as controls, in which the same volumes of $\mathrm{NaCl} 0.9 \%$ was infused. t-PA collected in coronary sinus was measured at baseline, during ischemia and at 1 and 5 min following reperfusion (balloon deflation). Reactive hyperemia t-PA measurements were only measured once in each pig. Blood gas analysis was performed at baseline and at 1 and 10 min following reperfusion in the 18 pigs treated with balloon-inflation.

\section{Protocol}

At baseline, measurements of blood pressure, pulse, APV and t-PA were performed. Blood pressure and pulse were measured continuously with coronary blood flow and APV analyzed once every ten seconds. A blood gas analysis was performed at baseline and at 1 and 5 min post-reperfusion. Blood samples were drawn from a peripheral artery and from the coronary sinus at baseline, during ischemia and at 1 and 5 min post-reperfusion.

\section{t-PA measurements}

Plasma concentrations of t-PA was determined by commercial ELISA kits (TintElize ${ }^{\circledR} \mathrm{t}-\mathrm{PA}$, Biopool AB, Umeå, Sweden and COALIZA ${ }^{\circledR}$ PAI, Chromogenix, Haemochrom Diagnostica $\mathrm{AB}$, Mölndal, Sweden). All samples from one experiment were assayed in duplicate on the same microtest plate. Intra-assay variation coefficients were $2.7 \%$ and $3.1 \%$ for respective assay. Plasma glucose, cholesterol, and triglycerides were analyzed by standard methods at the Department of Clinical Chemistry at Sahlgrenska University Hospital.

\section{Reagents}

Unless otherwise stated, drugs were purchased from Sigma Co, USA.

\section{Ethics}

The Ethics Committee of Lund University approved the project.

\section{Data analysis and statistics}

Calculations and statistics were performed using the GraphPad Prism 3.02 software. Values are presented as mean \pm SEM. Statistical significance was accepted when $p<0.05$ (twotailed test). One-way analysis of variance (ANOVA) test followed by the Dunnett multiple comparison test was used.

\section{Results}

\section{Infusion of ADP analogue and $\mathrm{P}_{2} \mathrm{Y}_{\mathbf{1}}$ antagonist in the non-ischemic heart}

Intracoronary infusion of the stable ADP agonist 2-MeSADP $\left(10^{-5} \mathrm{M}\right)$ at a rate of $1 \mathrm{ml} / \mathrm{min}$ caused a significant increase of the t-PA level in the coronary sinus compared to infusion of Ringers acetate (data not shown). The effects of 2-MeSADP $\left(10^{-5} \mathrm{M}, n=9\right)$ on t-PA release 
was significantly inhibited when infused together with the $\mathrm{P}_{2} \mathrm{Y}_{1}$ receptor antagonist MRS2179 $\left(10^{-3} \mathrm{M}, n=6\right)$ at a rate of $1 \mathrm{ml} / \mathrm{min}$. t-PA increased to a maximum (at $1 \mathrm{~min}$ ) of $1.81 \pm 0.32 \mathrm{ng} / \mathrm{ml}$ compared to $0.78 \pm 0.28 \mathrm{ng} / \mathrm{ml}$ in the presence of MRS2179, $p<0.05$ (Fig. 1a). t-PA was sampled selectively in coronary sinus. Following a 30 min washout period, the effects of 2-MeSADP on t-PA release could be repeated with similar results as during the initial infusion of 2-MeSADP $10^{-5} \mathrm{M}$ (data not shown). MRS 2179 alone did not have any effect on t-PA release (data not shown).

The effect was even more prominent when an estimation of total t-PA release was performed by factoring the measured t-PA level in the coronary sinus with measured blood flow in the LAD with a FloMap Doppler wire, (Fig. 1b). Continuous infusion of 2-MeSADP $\left(10^{-5} \mathrm{M}\right)$ at $1 \mathrm{ml} / \mathrm{min}$ increased flow in the LAD significantly as measured with the FloMap Doppler wire, as previously shown [19]. 2-MeSADP $\left(10^{-5} \mathrm{M}\right)$ jointly infused with MRS $2179\left(10^{-3} \mathrm{M}\right)$ at a rate of $1 \mathrm{ml} / \mathrm{min}$ did not significantly increase flow (data not shown). When release of t-PA was measured in the coronary sinus and factored with the measured flow in the LAD, there was a significant increase of t-PA release due to infusion of 2MeSADP. The estimate of differences in total t-PA release was calculated by multiplying with the relative increase in flow compare to baseline. Unfortunately this closed chest model does not allow determination of flow in $\mathrm{ml}$, only in peak velocity. However, our control experiments with angiographic measurements of vessel diameter during flow increase, demonstrated a minor increase in LAD vessel diameter. Thus, any error due to lack of correction for vessel diameter (i.e. quantification in $\mathrm{ml}$ ), would underestimate a flow increase and would thus if anything underestimate the findings of the article.

\section{Cardiac ischemia experiments}

There was no observed difference in t-PA levels in peripheral arterial samples from the femoral artery of t-PA during the baseline, ischemic or reperfusion periods, (Fig. 2). t-PA was measured in a peripheral artery (femoral artery) before, during and after coronary ischemia. Levels of t-PA in the peripheral arterial circulation were at these points unaffected by coronary infusion of MRS2179 during the first and tenth minute of coronary ischemia, $2.5 \mathrm{ml}$ of MRS $2179\left(10^{-3} \mathrm{M}\right)$.

t-PA release as measured in the Coronary Sinus increased during ischemia and reperfusion, an effect that was significantly inhibited by the ADP blocker MRS2179, (Fig. 3). t-PA was measured in the Coronary Sinus (venous) before, during and after 10 min of coronary ischemia. Measured levels of t-PA were significantly decreased during the later phase of ischemia and the early phase of reperfusion by coronary infusion of MRS 2179 during the first and tenth minute of coronary ischemia, $2.5 \mathrm{ml}$ of MRS $2179\left(10^{-3} \mathrm{M}\right) * p<0.05$.

Net t-PA release over the coronary bed was inhibited by the ADP P2Y1 receptor blocker MRS2179, (Fig. 4). t-PA was simultaneously measured in the Coronary Sinus (venous) and the femoral artery (arterial) before, during and after $10 \mathrm{~min}$ of coronary ischemia. The difference of measured levels of arterial and venous t-PA yielded a significantly decreased release of t-PA during the greater part of the ischemic period and the early phase of reperfusion by coronary infusion of MRS 2179 during the first and tenth minute of coronary ischemia, $2.5 \mathrm{ml}$ of MRS2179 $\left(10^{-3} \mathrm{M}\right)$. 
Post-ischemic flow in the LAD increased nearly seven-fold in the ten pigs treated with balloon inflation alone in the LAD (see Olivecrona et al purinergic signaling) [19], and net total t-PA release (factorial correction for blood flow, see above) in the coronary sinus was significantly decreased when MRS2179 was administered, Fig. 5. The greatest effect of MRS 2179 (to decrease measured levels of t-PA) during the ischemia-reperfusion phases occurred at $1 \mathrm{~min}$ after reperfusion. The same was observed regarding coronary flow in the LAD as previously reported [19]. A significant decrease of estimated relative total t-PA release corrected for flow changes was observed at $1 \mathrm{~min}$, but not at $5 \mathrm{~min}$ following reperfusion. Coronary LAD blood flow was abolished during ischemia due to the inflated balloon, making it impossible to estimate total t-PA release during this period.

During infusions of $\mathrm{NaCl}, 2-\mathrm{MeSADP}$ and MRS2179 there were no significant differences in blood pressure or pulse rate between the groups at the analyzed time intervals, (Table 1). There was no difference in basal t-PA levels or coronary flow rates between the group treated with MRS2179 and controls. The t-PA levels and the flow rates returned to initial values at the end of the experiments in all animals. The blood-gas samples analyzed of the 18 pigs in the occlusion/reperfusion group showed no statistical difference between the pigs receiving MRS2179 and the group treated as controls.

\section{Discussion}

We have for the first time shown that intra-coronary administration of the ADP analogue 2MeSADP increases release of t-PA in the coronary venous outflow via activation of endothelial coronary $\mathrm{P}_{2} \mathrm{Y}_{1}$ receptors. We have also for the first time shown that cardiac release of t-PA in response to cardiac ischemia can in turn be inhibited by selectively blocking the ADP receptor, $\mathrm{P}_{2} \mathrm{Y}_{1}$, with MRS2179.

The mechanism of t-PA release during reactive hyperemia is still not completely understood but appears to be multifactorial in origin. Earlier research on ischemic and post-ischemic release of t-PA in the heart has been performed both in vivo in large animals, as well as in ex-vivo cardiac models in rodents [3, 20, 21]. In large animals, in vivo models have shown that ischemia causes the release of t-PA and that this may be caused by a number of factors but seems to be independent of blood flow [3].

During severe coronary ischemia, as seen during and shortly following a coronary occlusion, ADP is released (or derived from ATP) from cardiac myocytes, endothelial cells, red blood cells, platelets and sympathetic nerves [22-24]. The ADP released into circulation in response to ischemia can thus stimulate release of t-PA, perhaps in part through the P2Y1 receptors. Endothelial $\mathrm{P}_{2} \mathrm{Y}_{1}$ receptors mediate SMC relaxation through EDHF [15, 17, 18]. NO and EDHF have been shown to mediate a large part of early reactive hyperemia [2528], and both are released by ADP acting on $\mathrm{P}_{2} \mathrm{Y}_{1}$ receptors [23, 29, 15, 18]. Furthermore, ATP infused in the human forearm (which results in formation of ADP as well), stimulates increased blood flow via EDHF and results in substantial release of t-PA [7]. Selective blockers of the $\mathrm{P}_{2} \mathrm{Y}_{1}$ receptors have recently become available [30], which made it possible to demonstrate that the ADP receptor $\mathrm{P}_{2} \mathrm{Y}_{1}$ mediates increases in blood flow during reactive 
hyperemia [16]. Now we wanted to examine the role of $\mathrm{P}_{2} \mathrm{Y}_{1}$ receptors during ischemic and post-ischemic release of t-PA.

The porcine in vivo model in our experiment was chosen because the presence of whole blood and a live model was essential. The use of angioplasty "over the wire" balloons allowed for precision in attaining both accurate and localized induction of ischemia, and delivery of infusions in a closed chest model. The physiological alterations induced by open chest experiments could thus be avoided. The infusion of Ringer's acetate solution at the same rate as later infusions of 2-MeSADP and MRS2179 did not alter measurements of flow from baseline. We found that the selective $\mathrm{P}_{2} \mathrm{Y}_{1}$ receptor agonist, the stable ADP analogue 2-MeSADP, induced a significant increased release of t-PA and as expected, a significant increase in coronary flow. However, both these findings could be completely abolished by simultaneous infusion of the selective $\mathrm{P}_{2} \mathrm{Y}_{1}$ receptor blocker MRS2179.

To test the contribution of $\mathrm{P}_{2} \mathrm{Y}_{1}$ receptors to the release of $\mathrm{t}-\mathrm{PA}$ during ischemia and during post-ischemic-hyperemia, the LAD was occluded, and MRS2179 was infused into the ischemic portion of the heart supplied by the LAD. This resulted in a significant reduction in t-PA release. This indicates that levels of ADP in the coronary circulation plays an important role in the regulation of local t-PA release in the heart by acting on $\mathrm{P}_{2} \mathrm{Y}_{1}$ receptors. Several earlier reports have suggested an important role for both extracellular nucleotides and EDHF in the release mechanism for t-PA $[11,12]$. Thus, ADP release could cause pro-fibrinolytic effects. This is however in stark contrast to the effect ADP has on platelets. ADP, in fact, activates platelets by stimulation of the $\mathrm{P}_{2} \mathrm{Y}_{1}$ (and $\mathrm{P}_{2} \mathrm{Y}_{12}$ ) receptors. Thus our findings indicate a dualistic action of ADP by means of a pro-fibrinolytic (by means t-PA release) and a counteracting prothrombotic (by means of platelet activation) role for ADP.

The effect of MRS2179 on ischemia induced t-PA release is only partial. Other mechanisms than the $\mathrm{P}_{2} \mathrm{Y}_{1}$-receptor that could explain the remaining effect include other $\mathrm{P} 2$-receptors, such as $\mathrm{P}_{2} \mathrm{Y}_{2}, \mathrm{P}_{2} \mathrm{Y}_{6}$ or $\mathrm{P} 2 \mathrm{X}_{4}$ which are expressed in the endothelium. Furthermore, novel mechanisms of ADP mediating relaxation in pig coronary arteries via adenosine release have recently been described and could be involved [31].

In conclusion, our experiments suggest that $\mathrm{ADP}$ stimulating $\mathrm{P}_{2} \mathrm{Y}_{1}$ receptors mediate a major part of the cardiac release of t-PA seen during coronary ischemia and during the subsequent reactive hyperemia in the heart. This may counter-balance the well-known platelet stimulating effects of ADP during acute myocardial ischemia. It is possible that the inhibitor of ADP induced platelet aggregation, clopidogrel (Plavix), shifts this balance in favor of the fibrinolytic ADP effects described here.

\section{Acknowledgments}

The study was supported by the Swedish Heart and Lung Foundation, the Vascular Wall program fund, the Franke and Margareta Bergqvist Foundation, the Zoegas Foundation, the Westergren Foundation, the Swedish Medical Society, and the Swedish Medical Research Council, Grant 13130. We would especially like to thank nurse Pernilla Jarnhall for all her assistance during the animal experiments. We would like to thank Boston Scientific Cardiology, Nordic AB (Helsingborg, Sweden) for their generosity in unrestricted donations of catheters and guide wires for use in animal research. 


\section{References}

1. van Hinsbergh VW, Binnema D, Scheffer MA, Sprengers ED, Kooistra T, Rijken DC. Production of Plasminogen activators and inhibitors by serially propagated endothelial cells from adult human blood vessels. Arteriosclerosis. 1987; 7:389-400. [PubMed: 3300618]

2. Wang Y, Hand AR, Wang YH, Mina M, Gillies C, Peng T, Cone RE, O'Rourke J. Functional and morphologic evidence of the prescence of tissue-plasminogen activator in vascular nerves: implications for neurologic control of vessel wall fibrinolysis and rigidity. J Neurosci Res. 1998; 53:443-453. [PubMed: 9710264]

3. Osterlund B, Jern C, Seeman-Lodding H, Johansson G, Haggmark S, Broome M, Biber B. Intracoronary beta2 receptor activation induces dynamic local t-PA release in the pig. Thromb Haemost. 2003; 90:796-802. [PubMed: 14597973]

4. Tranquille N, Emeis JJ. The simultaneous acute release of tissue-type plasminogen activator and von Wille-brand factor in the perfused rat hindleg region. Thromb Haemost. 1990; 63:454-458. [PubMed: 2119527]

5. Hrafnkelsdottir T, Gudnason T, Wall U, Jern C, Jern S. Regulation of local availability of active tissue-type plasminogen activator in vivo in man. J Thromb Haemost. 2004; 2:1960-1968. [PubMed: 15550028]

6. Witherow FN, Dawson P, Ludlam CA, Fox KA, Newby DE. Marked bradykinin-induced tissue plasminogen activator release in patients with heart failure maintained on long-term angiotensinconverting enzyme inhibitor therapy. J Am Coll Cardiol. 2002; 40:961-966. [PubMed: 12225723]

7. Hrafnkelsdottir T, Erlinge D, Jern S. Extracellular nucleotides ATP and UTP induce a marked acute release of tissue-type plasminogen activator in vivo in man. Thromb Haemost. 2001; 85:875-81. [PubMed: 11372682]

8. Smalley DM, Fitzgerald JE, O'Rourke J. Adenosine diphosphate stimulates the endothelial release of tissue-type plasminogen activator but not von Willebrand factor from isolated-perfused rat hind limbs. Thromb Haemost. 1993; 70:1043-1046. [PubMed: 8165598]

9. Bjorkman JA, Jern S, Jern C. Cardiac sympathetic nerve stimulation triggers coronary t-PA release. Arterioscler Thromb Vasc Biol. 2003; 23:1091-1097. [PubMed: 12714432]

10. Aspelin T, Eriksen M, Lindgaard AK, Lyberg T, Ilebekk A. Cardiac fibrinolytic capacity is markedly increased after brief periods of local myocardial ischemia, but declines following successive periods in anesthetized pigs. J Thromb Haemost. 2005; 3:1947-1954. [PubMed: 16102101]

11. Osterlund B, Andersson B, Haggmark S, Jern C, Johansson G, Seeman-Lodding H, Biber B. Myocardial ischemia induces coronary t-PA release in the pig. Acta Anaesthesiol Scand. 2002; 46:271-278. [PubMed: 11939917]

12. Brown NJ, Gainer JV, Murphey LJ, Vaughan DE. Bradykinin stimulates tissue plasminogen activator release from human forearm vasculature through $\mathrm{B}(2)$ receptor-dependent, NO synthaseindependent, and cyclooxygenase-independent pathway. Circulation. 2000; 102:2190-2196. [PubMed: 11056091]

13. Kelly KO, Gould KL. Coronary reactive hyperemia after brief occlusion and after deoxygenated perfusion. Cardiovasc Res. 1981; 15:615-622. [PubMed: 7326681]

14. Kuzmin AI, Lakomkin VL, Kapelko VI, Vassort G. Interstitial ATP level and degradation in control and post-myocardial rats. Am J Physiol. 1998; 275:C766-C711. [PubMed: 9730960]

15. Wihlborg AK, Malmsjo M, Eyjolfsson A, Gustafsson R, Jacobson K, Erlinge D. Extracellular nucleotides mediate vasodilation in human arteries via prostaglandin, nitric oxide and endothelium dependent hyperpolarising factor (EDHF). Br J Pharmacol. 2003; 138:1451-1458. [PubMed: 12721100]

16. Daniel JL, Dangelmaier C, Jin J, Ashby B, Smith B, Kunapuli SP. Molecular basis for ADPinduced platelet activation. I. Evidence for three distinct ADP receptors on platelets. J Biol Chem. 1998; 273:2024-2029. [PubMed: 9442039]

17. Malmsjo M, Erlinge D, Hogestatt ED, Zygmunt PM. Endothelial P2Y receptors induce hyperpolarisation of vascular smooth muscle by release of endothelium-derived hyperpolarising factor. Eur J Pharmacol. 1999; 364:169-173. [PubMed: 9932720] 
18. Malmsjo M, Edvinsson L, Erlinge D. P2U-receptor mediated endothelium-dependent but nitric oxide-independent vascular relaxation. Br J Pharmacol. 1998; 123:719-729. [PubMed: 9517392]

19. Olivecrona GK, Gotberg M, Harnek J, Wang LW, Jacobson KA, David Erlinge D. Coronary artery reperfusion: the ADP receptor $\mathrm{P} 2 \mathrm{Y} 1$ mediates early reactive hyperemia in vivo in pigs. Purinergic Signal. 2004; 1:59-64. [PubMed: 18404401]

20. Winnerkvist A, Wiman B, Valen G, Vaage J. Release of tissue plasminogen activator during reperfusion after different times of ischaemia in isolated, perfused rat hearts. Thromb Res. 1996; 82:533-542. [PubMed: 8794525]

21. Winnerkvist A, Wiman B, Valen G, Vaage J. Oxidative stress and release of tissue plasminogen activator in isolated rat hearts. Thromb Res. 1997; 85:245-57. [PubMed: 9058499]

22. Burnstock G. Vascular control by purines with emphasis on the coronary system. Eur Heart J Suppl F. 1989:15-21.

23. Ralevic V, Burnstock G. Receptors for purines and pyrimidines. Pharmacol Rev. 1998; 50:413492. [PubMed: 9755289]

24. Burnstock G. Hypoxia, endothelium and purines. Drug Dev Res. 1993; 28:301-305.

25. Aversano T, Ouyang P, Silverman H. Blockade of the ATP-sensitivepotassium channel modulates reactive hyperaemia in the canine coronary circulation. Circ Res. 1991; 69:618-622. [PubMed: 1651815]

26. Yamabe H, Okumura K, Ishizaka H, Tsuchiya T, Yasue H. Role of endothelium-derived nitric oxide in myocar-dial reactive hyperemia. Am J Physiol. 1992; 263:8-14.

27. Zatta, A.; Headrick, J. Proceedings of the 4th international symposium of nucleosidesand nucleotides. Vol. 133. Chapel Hill, NC, USA: Jun 6-9. 20042004 Roles of A2 adenosine receptors, K+ATPchannels, NO and EDHF in coronary reactive hyperemia.; p. $98 \mathrm{~W}$

28. Gryglewski RJ, Chlopicki S, Niezabitowski P, Jakubowski A, Lomnicka M. Ischaemic cardiac hyperaemia: Role of nitric oxide and other mediators. Physiol Res. 1996; 45:255-260. [PubMed: 9085346]

29. Malmsjo M, Erlinge D, Hogestatt ED, Zygmunt PM. Endothelial P2Y receptors induce hyperpolarisation of vascular smooth muscle by release of endothelium-derived hyperpolarising factor. Eur J Pharmacol. 1999; 364:169-173. [PubMed: 9932720]

30. Moro S, Guo D, Camaioni E, Boyer JL, Harden TK, Jacobson KA. Human P2Y1 receptor: molecular modeling and site-directed mutagenesis as tools to identify agonist and antagonist recognition sites. J Med Chem. 1998; 41:1456-1466. [PubMed: 9554879]

31. Rayment SJ, Ralevic V, Barret DA, Cordell R, Alexander SP. A novel mechanism of vasoregulation: ADP-induced relaxation of the porcine isolated coronary artery is mediated via adenosine release. FASEB J. 2007; 21 Published online December 13, 2006. 


\section{Abbreviated Abstract}

We postulated that the release of t-PA during post ischemic reactive hyperemia could be mitigated through blocking the coronary endothelial $\mathrm{P}_{2} \mathrm{Y}_{1}$ receptor in a porcine model. The ADP analogue 2-MeSADP $\left(10^{-5} \mathrm{M}\right)$, alone or as co-infusion with a the P2 $\mathrm{Y}_{1}$ receptor blocker, MRS2179 $\left(10^{-3} \mathrm{M}\right)$ was locally delivered in the left anterior descending artery. In separate pigs the coronary artery was occluded for ten min. During the first and tenth min of coronary ischemia, $2.5 \mathrm{ml}$ of MRS2179 $\left(10^{-3} \mathrm{M}\right)$ was delivered distal to the occlusion. t-PA was measured in peripheral arterial blood and also from the Coronary Sinus. We found that levels of t-PA in the blood from the coronary Sinus increased during infusion with 2-MeSADP as well as during ischemia and reperfusion. In pigs treated with MRS2179 levels of t-PA in the Coronary Sinus were significantly reduced during both coinfusion with 2-MeSADP and during ischemia/reperfusion. Thus, ADP acting on the endothelial $\mathrm{P}_{2} \mathrm{Y}_{1} \mathrm{M}$ receptor may mediate release of t-PA during ischemia and post-ischemic hyperemia, an effect that may counteract some of the platelet activating effects of ADP. 


\section{t-PA release}

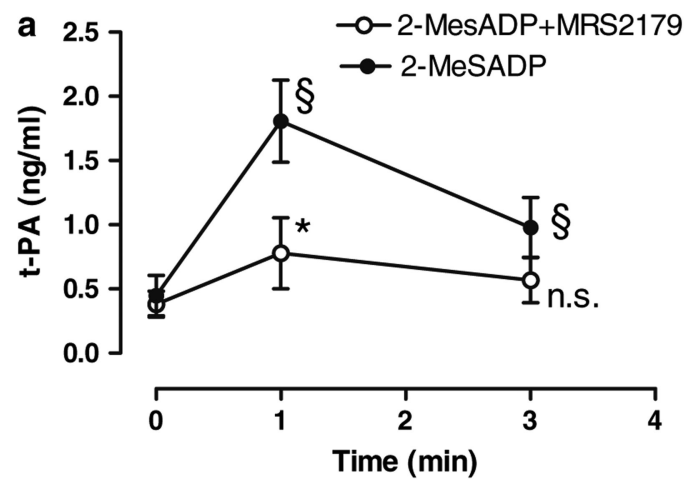

$\S \quad=p<0.05$ compared to baseline t-PA
$\star \quad=p<0.05$ compared to 2-MeSADP alone

t-PA*flow

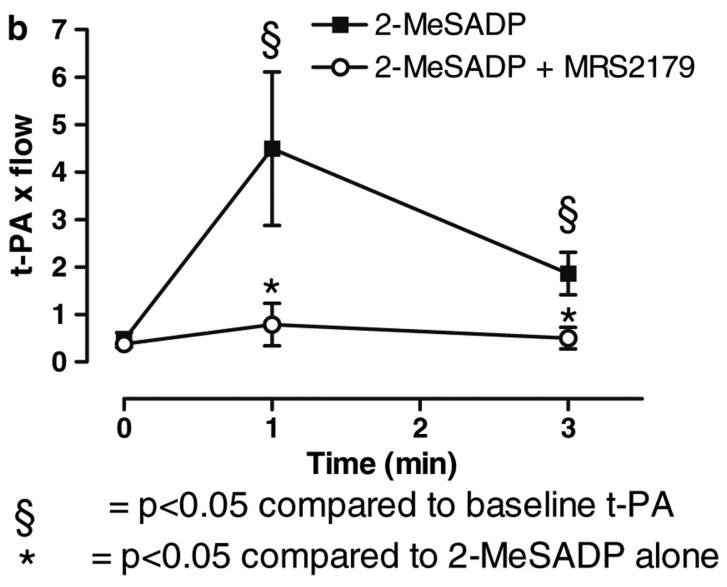

Fig. 1.

(A) Illustrates that an ADP analogue release t-PA in the pig coronary circulation and that the effect is mediated by the $\mathrm{P} 2 \mathrm{Y} 1$ receptor: Release of t-PA due to continuous intracoronary infusion of 2-MeSADP $\left(10^{-5} \mathrm{M}\right)(1 \mathrm{ml} / \mathrm{min})$ alone (filled circles, $\left.n=9\right)$, or 2-MeSADP $\left(10^{-5} \mathrm{M}\right)$ jointly infused with the P2Y1 antagonist MRS2179 $\left(10^{-3} \mathrm{M}\right)$ at a rate of $1 \mathrm{ml} / \mathrm{min}$ (open circles, $n=6$ ). t-PA was sampled selectively in the coronary sinus. ${ }^{*} p<0.05$ compared to baseline. ${ }^{\S} \mathrm{p}<0.05$ compared to 2-MeSADP alone. (B) Illustrates an estimate of differences in total t-PA release: Continuous infusion of 2-MeSADP $\left(10^{-5} \mathrm{M}\right)$ at 1 $\mathrm{ml} / \mathrm{min}$ increased flow in the LAD significantly as measured with the FloMap Doppler wire (data not shown). 2-MeSADP $\left(10^{-5} \mathrm{M}\right)$ jointly infused with MRS $2179\left(10^{-3} \mathrm{M}\right)$ at a rate of $1 \mathrm{ml} / \mathrm{min}$ did not increase flow. When release of t-PA was measured in the coronary sinus and factored with the measured flow in the LAD, there was a significant increase of t-PA release due to infusion of 2-MeSADP. The estimate of differences in total t-PA release was calculated by multiplying with the relative increase in flow compare to baseline 


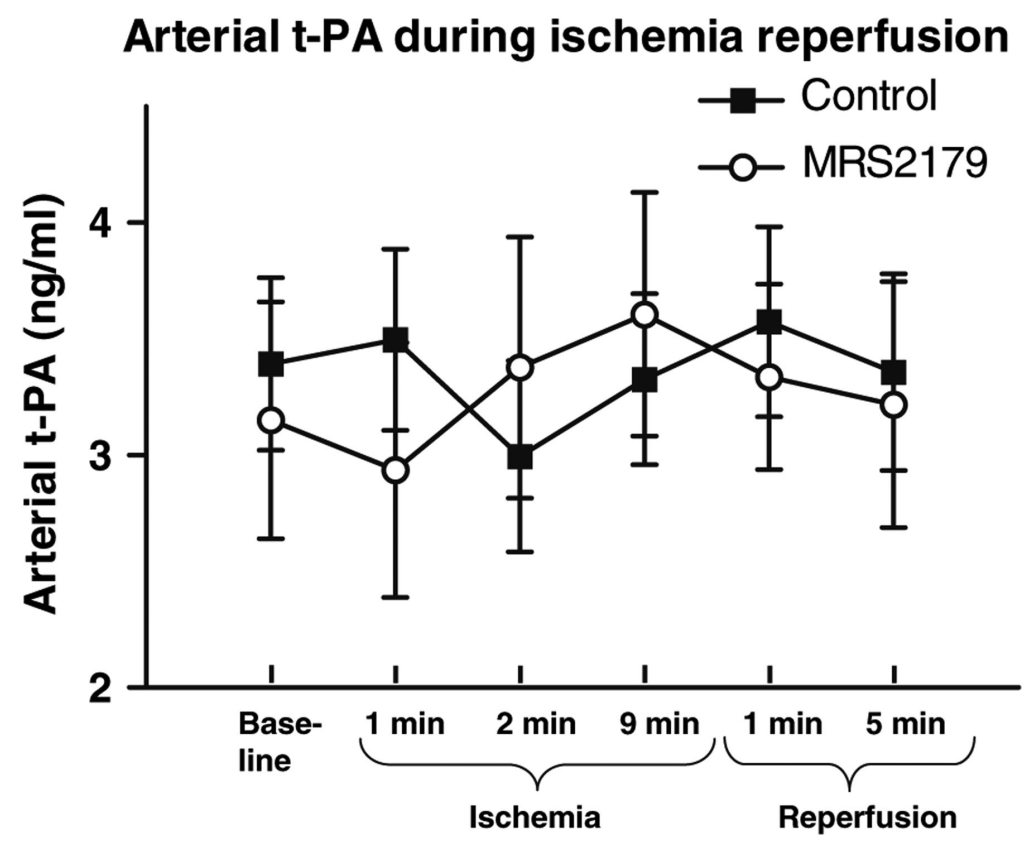

Fig. 2 .

No systemic changes in t-PA concentrations during ischemia were observed: t-PA was measured in a peripheral artery (femoral artery) before, during and after coronary ischemia. Levels of t-PA in the peripheral arterial circulation were at these points unaffected by coronary infusion of $2.5 \mathrm{ml}$ of MRS2179 $\left(10^{-3} \mathrm{M}\right)$ during the first and tenth minute of coronary ischemia 


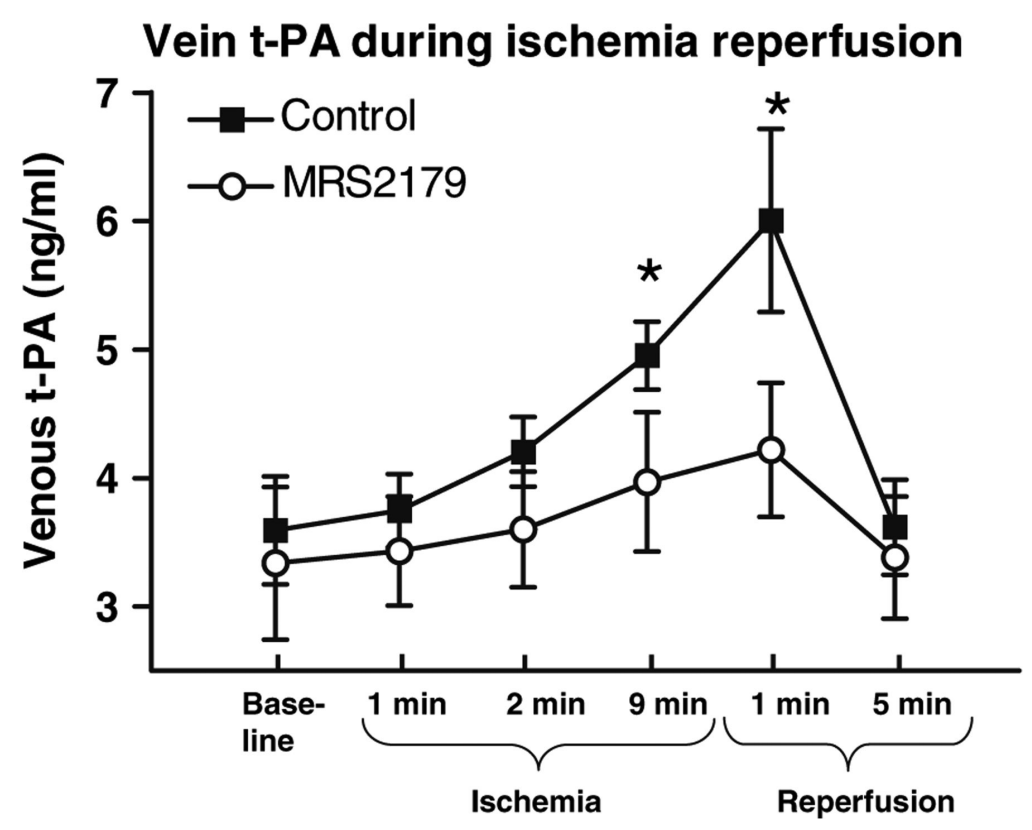

Fig. 3.

The t-PA released during ischemia and reperfusion is partly inhibited by the ADP P2Y1 receptor blocker MRS2179: t-PA was measured in the coronary sinus (venous) before, during and after 10 min of coronary ischemia and increased significantly $(n=8, p<0.05)$. Measured levels of t-PA were significantly decreased during the later phase of ischemia and the early phase of reperfusion by coronary infusion of MRS2179 during the first and tenth minute of coronary ischemia, $n=7, * p<0.05$ 


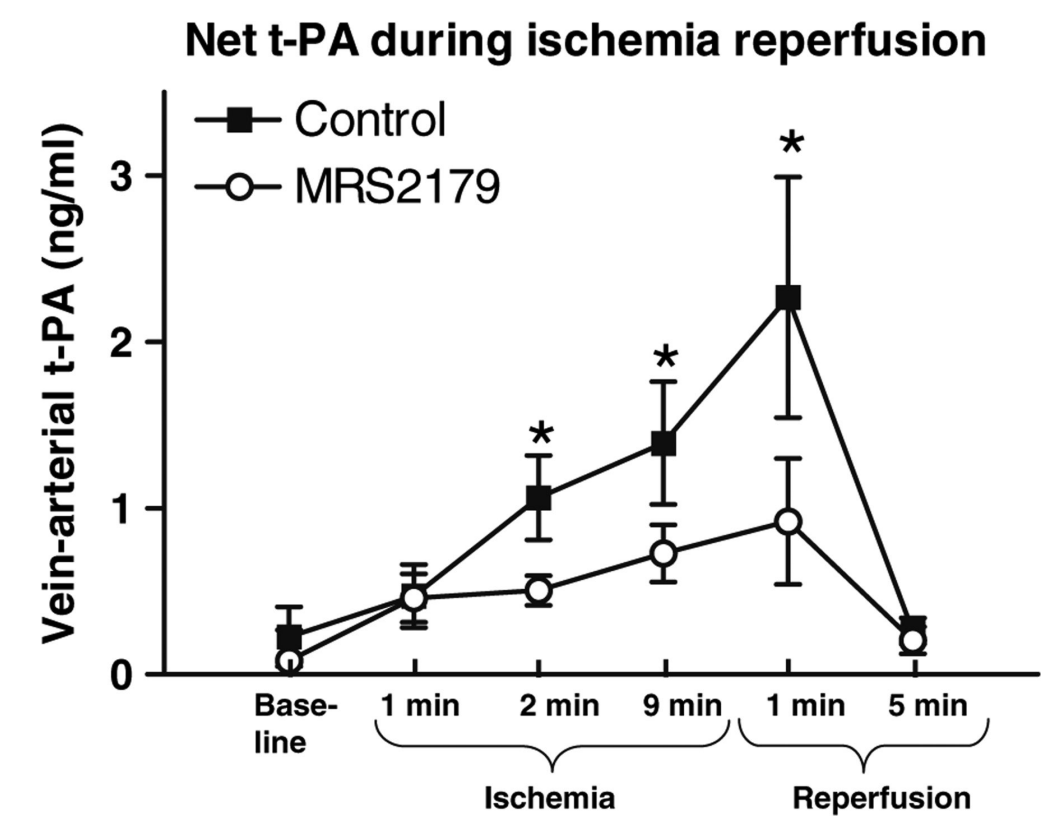

Fig. 4.

Net t-PA release over the coronary bed was inhibited by the ADP P2Y1 receptor blocker MRS2179: t-PA was simultaneously measured in the coronary sinus (venous) and the femoral artery (arterial) before, during and after $10 \mathrm{~min}$ of coronary ischemia. The difference of measured levels of arterial and venous t-PA yielded a significantly decreased release of t-PA during the greater part of the ischemic period and the early phase of reperfusion by coronary infusion of MRS2179 during the first and tenth minute of coronary ischemia $\left(2.5 \mathrm{ml}\right.$ of MRS2179, $\left.10^{-3} \mathrm{M}\right) . n=7-8, * p<0.05$ 


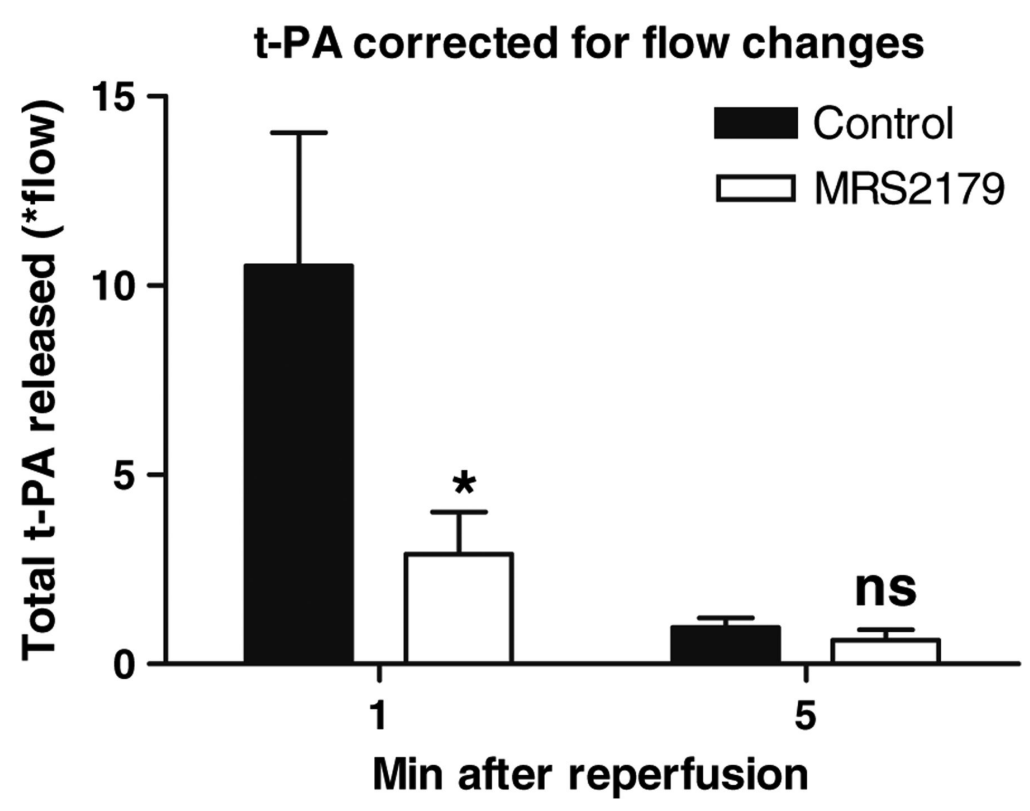

Fig. 5.

An estimate of relative changes in total t-PA release: The greatest effect of MRS2179 to decrease measured levels of t-PA during the ischemia-reperfusion phases occurred at $1 \mathrm{~min}$ after reperfusion. The same was observed regarding coronary flow in the LAD as previously reported [19]. This figure illustrates the arterial venous difference factored with the measured flow in the LAD at 1 and 5 min following reperfusion. A significant decrease of total t-PA release corrected for flow changes was measured at $1 \mathrm{~min}$, but not at $5 \mathrm{~min}$ following reperfusion. Coronary LAD blood flow was abolished during ischemia, making it impossible to estimate total t-PA release during this period. $n=7-8,{ }^{*} p<0.05$ 
Table 1

Arterial blood-gas analysis of pigs with occlusion and reperfusion of a coronary vessel treated with MRS 2179 $(n=8)$ or used as controls $(n=10)$

\begin{tabular}{lccccccc}
\hline & Baseline & & \multicolumn{2}{c}{ 1 min reperfusion } & & \multicolumn{2}{c}{ 5 min reperfusion } \\
\cline { 2 - 3 } & Control & MRS2179 & Control & MRS2179 & & Control & MRS2179 \\
\hline $\mathrm{PH}$ & $7.48 \pm 0.04$ & $7.49 \pm 0.04$ & $7.46 \pm 0.06$ & $7.48 \pm 0.04$ & & $7.46 \pm 0.07$ & $7.47 \pm 0.03$ \\
$\mathrm{pCO} 2$ & $5.4 \pm 0.7$ & $5.3 \pm 0.5$ & $5.6 \pm 0.9$ & $5.3 \pm 0.5$ & $5.3 \pm 0.6$ & $5.3 \pm 0.7$ \\
$\mathrm{pO} 2$ & $46.5 \pm 17.1$ & $44.5 \pm 15.4$ & $41.3 \pm 13.4$ & $44.3 \pm 18.2$ & $35.9 \pm 3.6$ & $36.2 \pm 4.1$ \\
$\mathrm{Na}^{+}$ & $133 \pm 2$ & $135 \pm 1$ & $133 \pm 1$ & $134 \pm 2$ & $133 \pm 2$ & $135 \pm 2$ \\
$\mathrm{~K}^{+}$ & $3.5 \pm 0.3$ & $3.6 \pm 0.3$ & $3.5 \pm 0.2$ & $3.7 \pm 0.3$ & $3.5 \pm 0.2$ & $3.6 \pm 0.1$ \\
$\mathrm{Hb}$ & $89 \pm 7$ & $91 \pm 3$ & $91 \pm 6$ & $92 \pm 5$ & $89 \pm 4$ & $92 \pm 4$ \\
$\mathrm{O}_{2}$ & $97.1 \pm 0.2$ & $97.2 \pm 0.2$ & $97.6 \pm 1.3$ & $97.4 \pm 0.4$ & $97.3 \pm 0.1$ & $97.2 \pm 0.2$ \\
$\mathrm{HCO}_{3}$ & $29.0 \pm 1.7$ & $30.0 \pm 0.4$ & $28.7 \pm 1.4$ & $29.6 \pm 0.4$ & $28.5 \pm 1.2$ & $29.3 \pm 0.8$ \\
$\mathrm{Base}$ & $5.7 \pm 0.7$ & $6.1 \pm 0.3$ & $4.9 \pm 0.9$ & $5.5 \pm 0.4$ & $5.2 \pm 0.6$ & $5.4 \pm 0.5$ \\
\hline
\end{tabular}

Samples were collected at baseline and at 1 and 5 min following reperfusion. There were no statistical differences between pigs treated with MRS 2179 or pigs used as controls. Data are expressed as mean \pm SEM, $p=$ NS 